Check for updates

Cite this: RSC Adv., 2018, 8, 24236

\title{
Oxidized multiwall carbon nanotube/silicone foam composites with effective electromagnetic interference shielding and high gamma radiation stability $\dagger$
}

\author{
Furong Huang, ${ }^{\text {a } Y i m e n g ~ W a n g, ~}{ }^{\text {a }}$ Peiyu Wang, ${ }^{\mathrm{b}}$ Hui-ling Ma, ${ }^{\mathrm{C}}$ Xibang Chen, ${ }^{\mathrm{a}} \mathrm{Ke} \mathrm{CaO},{ }^{\mathrm{c}}$ \\ Yongmao Pei, ${ }^{b}$ Jing Peng, ${ }^{a}$ Jiuqiang $\mathrm{Li}^{\mathrm{a}}$ and Maolin Zhai ${ }^{*}{ }^{* a}$
}

\begin{abstract}
Oxidized multiwall carbon nanotubes (o-MWCNTs) were introduced into silicone foam to fabricate an electromagnetic interference (EMI) shielding material with high gamma radiation stability by solution casting followed by foaming and cross-linking reactions. The as-prepared o-MWCNT/silicone foam composites exhibited excellent mechanical strength and effective EMI shielding properties with superior EMI shielding effectiveness (SE) ranging from 26 to $73 \mathrm{~dB}$ at a 0.5-6.4 mm thickness with 30 wt\% oMWCNTs in the $K_{\mathrm{u}}$ band. Moreover, the composites have good gamma radiation stability, showing relatively stable EMI shielding properties and an improvement of hardness and pressure resistance after gamma irradiation with the absorbed dose of $500 \mathrm{kGy}$. These results indicate that the o-MWCNT/ silicone foam composite is an attractive candidate for EMI shielding in some ionizing radiation environments.
\end{abstract}

Received 18th April 2018

Accepted 29th June 2018

DOI: $10.1039 / \mathrm{c} 8 \mathrm{ra03314e}$

rsc.li/rsc-advances
Recently, conductive polymer composites (CPCs) as EMI shielding materials have attracted broad attention due to their light weight, ease of fabrication, good stability and low cost., Solution casting is a common dispersion technique for the preparation of CPC EMI shielding materials because of the well dispersion of conductive fillers in polymer matrices and the prevention of damage to fillers. ${ }^{7}$ Multiwall carbon nanotubes (MWCNTs), possessing a very high aspect ratio and extraordinary conductivity, are widely used as conductive fillers in polymers and applied to EMI shielding. ${ }^{8} \mathrm{M}$. H. Al-Saleh et al. compared the EMI SE of acrylonitrile-butadiene-styrene (ABS) with three different carbon nanofillers, finding that MWCNTs exhibited the highest EMI SE. ${ }^{9}$ However, the poor dispersion of MWCNTs caused by their entanglement and lack of interfacial compatibility with polymers, will give rise to damage in the EMI shielding performance of polymer composites. It has been reported that the oxidation of MWCNTs could introduce functional groups such as carboxylic and carbonyl groups on their surface, which could form hydrogen bonding interactions with polymer and lead to a better dispersion of o-MWCNTs in polymer matrices. ${ }^{10,11}$ Therefore, the polymers filled with oMWCNTs may exhibited better EMI shielding performance.

Furthermore, EMI shielding materials are widely used in satellite communications and military applications such as weapon-locating radar. Consequently, the gamma rays generated from the space and nuclear radiation environment, would not only decrease the EMI shielding performance of shielding materials, but also destroy the mechanical structures of
Beijing National Laboratory for Molecular Sciences, Radiochemistry and Rad Chemistry Key Laboratory of Fundamental Science, The Key Laboratory of Polymer Chemistry and Physics of the Ministry of Education, College of Chemistry and pku.edu.cn

${ }^{b}$ State Key Laboratory for Turbulence and Complex Systems, College of Engineering, Peking University, Beijing 100871, China

${ }^{c}$ Beijing Key Laboratory of Radiation Advanced Materials, Beijing Research Center for Radiation Application, Beijing 100015, China

$\dagger$ Electronic supplementary information (ESI) available. See DOI: 10.1039/c8ra03314e 
polymer matrix. ${ }^{12}$ Thus, it is crucial to fabricate an EMI shielding material with high ionizing radiation stability. Silicone rubber foam, consisting of $\mathrm{Si}-\mathrm{O}$ bonds in the main chain, has advantages over other polymers including great resistance to damage from extreme temperature, radiation, weather and chemicals. ${ }^{13}$ The foam structure provides the silicone rubber with low density as well as shock and impact resistance. According to the literatures, the introduction of foam structure can further increase the SE by enhancing the multiple reflections of electromagnetic waves. ${ }^{\mathbf{1 4 - 1 6}}$ Therefore, o-MWCNT/ silicone foam composites are hopeful to be used in the space and nuclear radiation environment as shielding materials. In addition, the ionizing radiation stability of shielding materials should be examined. However, few studies have been reported on the effect of ionizing radiation on shielding materials to the best of our knowledge.

In this study, functionalized MWCNTs were used to produce o-MWCNT/silicone foam composites by solution casting followed by foaming and cross-linking reactions. O-MWCNT/ silicone foam composites with wide ranges of o-MWCNT content from 1 to $30 \mathrm{wt} \%$ and thicknesses from 0.5 to $6.5 \mathrm{~mm}$ were prepared successfully. The EMI shielding, dielectric and mechanical properties of the composites were systematically investigated. Moreover, the effect of gamma radiation on $\mathrm{O}^{-}$ MWCNT/silicone foam composites was evaluated with the absorbed dose from 100 to $500 \mathrm{kGy}$.

\section{Experimental}

\section{Materials}

MWCNTs were purchased from Shenzhen Nanotech Port Co. Ltd, synthesized by catalytic CVD process. Their specifications are as follows: purity, >95\%; outer diameter, $20-40 \mathrm{~nm}$; length, 5-15 $\mu \mathrm{m}$; specific surface area, 40-300 $\mathrm{m}^{2} \mathrm{~g}^{-1}$; tap density, 0.15$0.28 \mathrm{~g} \mathrm{~cm}^{-3}$; ash, $\leq 0.2 \mathrm{wt} \%$; amorphous carbon, $<3 \%$.

The $65 \%$ nitric acid of guaranteed grade and 95\% sulfuric acid of analytical grade were obtained from Xilong Scientific Co Ltd. Tetrahydrofuran (THF) of analytical grade was obtained from the Beijing Chemical Works.

Silicone foam reactants were kindly supplied by Bluestar Silicones as a two-part system (Rhodorsil RT Foam 3240).

\section{Preparation of o-MWCNT/silicone foam composites}

The detailed oxidation process of MWCNTs is given in ESI. $\dagger$ Solution casting method was used to prepare the silicone foam with different content of o-MWCNTs. O-MWCNTs were dispersed in THF under magnetic stirring and subjected to probe sonication by a Y99-2 DN ultrasonicator (Ningbo, China) for $1 \mathrm{~h} .1 \mathrm{~g}$ of part A component was added to the o-MWCNT/ THF and left stirring overnight. After THF was evaporated at $40{ }^{\circ} \mathrm{C}$ until constant weight was achieved, $1 \mathrm{~g}$ of part $\mathrm{B}$ component was thoroughly mixed with the o-MWCNT/part A mixture. The final sample was poured into a rectangular mould and foaming took place at room temperature. Silicone foams containing 1, 5, 10, 20 and $30 \mathrm{wt} \%$ o-MWCNTs were prepared.

\section{Gamma radiation effect of o-MWCNT/silicone foam composites}

The silicone foam composites were sealed in the glass tube and directly irradiated using $\gamma$-rays from a ${ }^{60} \mathrm{Co}$ source at the Department of Applied Chemistry of Peking University with the absorbed doses from 100 to 500 kilogray (kGy) at ambient temperature.

\section{Characterization of o-MWCNT/silicone foam composites}

EMI SE was characterized using an Agilent E8363C Phasor Network Analyzer (PNA) in the 12.4-18 GHz ( $\mathrm{K}_{\mathrm{u}}$-band) range, which is applied to satellite communications and military applications. The dimensions of the sample holder taken for shielding measurements were as follows: length, $15.72 \mathrm{~mm}$, width, $7.82 \mathrm{~mm}$ and thickness, $6.48 \mathrm{~mm}$. The samples were measured in triplicate to get an average. The scattering parameters ( $S$ parameters) $\left(S_{11}, S_{12}, S_{21}\right.$ and $\left.S_{22}\right)$ were recorded over the $\mathrm{K}_{\mathrm{u}}$-band frequency range. Then the total $\mathrm{SE}\left(\mathrm{SE}_{\mathrm{T}}\right)$, shielding by reflection $\left(\mathrm{SE}_{\mathrm{R}}\right)$ and absorption $\left(\mathrm{SE}_{\mathrm{A}}\right)$ were calculated by eqn (1)-(3) based on the $S$ parameters.

$$
\begin{gathered}
\mathrm{SE}_{\mathrm{T}}=10 \log \frac{1}{\left|S_{12}\right|^{2}} \\
\mathrm{SE}_{\mathrm{A}}=10 \log \left(\frac{1-\left|S_{11}\right|^{2}}{\left|S_{12}\right|^{2}}\right) \\
\mathrm{SE}_{\mathrm{R}}=10 \log \left(\frac{1}{1-\left|S_{11}\right|^{2}}\right)
\end{gathered}
$$

Scanning electron microscopy (SEM) analysis was performed at an accelerating voltage of $2 \mathrm{kV}$ on a Hitachi S-4800 field emission scanning electron microscopy (FESEM). The compressive strength of the samples was tested by universal material testing instrument (Instron 3365). Silicone foam cylinders with the size of $\Phi 10.5 \times 2.5 \mathrm{~mm}$ were prepared. The compressive test was conducted with a constant strain rate of 1 $\mathrm{mm} \min ^{-1}$ until $80 \%$ reduction in specimen height. The samples were measured in triplicate to get an average. Compressive modulus was calculated as the slope of the initial linear potion of the curve. The thermal analysis (TA) was recorded with a Q600-SDT instrument (TA Instruments, America) in the nitrogen gas atmosphere, over a temperature range of $30-800{ }^{\circ} \mathrm{C}$ with a heating rate of $10{ }^{\circ} \mathrm{C} \mathrm{min}^{-1}$. X-ray photoelectron spectroscopy (XPS) spectra were recorded on an AXIS-Ultra Imaging Photoelectron Spectrometer from Kratos Analytical Ltd., which used monochromatic Al-K $\alpha$ radiation under a vacuum of $2 \times 10^{-8} \mathrm{~Pa}$.

\section{Results and discussion}

\section{Synthesis and characterization of silicone foam and o- MWCNTs}

Silicone foam is prepared by foaming and cross-linking reactions, which occur simultaneously. The foaming reaction 
between $\mathrm{Si}-\mathrm{H}$ and $\mathrm{Si}-\mathrm{OH}$ groups and cross-linking reaction between the vinyl end blocked groups and $\mathrm{Si}-\mathrm{H}$ groups take place in the presence of platinum (Pt) catalyst with the generation of hydrogen gas.

The surface area of pristine MWCNTs is so large that strong attractive forces existed between the MWCNTs, which undesirably induces the agglomeration and entanglement of MWCNTs. Besides, the pristine MWCNTs are lack of interfacial adhesion with polymer materials. In order to improve the compatibility between MWCNTs and silicone foam matrix, MWCNTs were oxidized by refluxing with a mixture of $\mathrm{HNO}_{3} / \mathrm{H}_{2} \mathrm{SO}_{4}$. The oMWCNTs were dispersed more uniformly than MWCNTs in THF, as shown in Fig. S1. $\dagger$ The oxidative treatment of MWCNTs led to an increase in the atomic oxygen percentage from $1.59 \%$ to $9.32 \%$, which was confirmed by XPS (Fig. S2a and c $\dagger$ ). According to XPS C 1s spectra (Fig. S2b and $d \dagger$ ), the amount of $\mathrm{COOH}$ and $\mathrm{sp}^{3} \mathrm{C}-\mathrm{C}$ increased, while $\mathrm{C}-\mathrm{OH}$ decreased after the oxidation reaction, which further demonstrated the oxidation of MWCNTs. From Fig. S3, $\uparrow$ we can see that o-MWCNTs exhibited a weight loss of $13.7 \%$, which was attributed to the decarboxylation of carboxyl groups and the elimination of hydroxyl groups present on the MWCNT walls. These oxygen-containing groups of o-MWCNTs could form hydrogen bonding with $\mathrm{Si}-\mathrm{OH}$ groups in silicone foam, so the interfacial adhesion between the o-MWCNTs and silicone foam would be enhanced.

\section{EMI SE analysis}

EMI SE quantitatively describes the EMI shielding ability of the materials. ${ }^{17}$ The EMI SE is significantly influenced by the dispersion of filler in the polymer matrix. ${ }^{18}$ For comparison, the EMI SE of the pristine MWCNT/silicone foam and o-MWCNT/ silicone foam composites were measured, as shown in the Fig. 1a. The o-MWCNT/silicone foam composite displayed a better EMI SE than the pristine MWCNT/silicone foam composite. It is attributed to that o-MWCNTs could interact with $\mathrm{Si}-\mathrm{OH}$ groups of silicone foam to form hydrogen bonding, which improves the dispersion of o-MWCNTs and leads to the formation of more interconnected conductive networks in the silicone foam. In addition, the dispersed solvent not only affects the dispersion of o-MWCNTs, but also influences the solubility of part A for forming silicone foam. From Fig. 1b, the composite prepared by using THF as the dispersed solvent presented the (a)

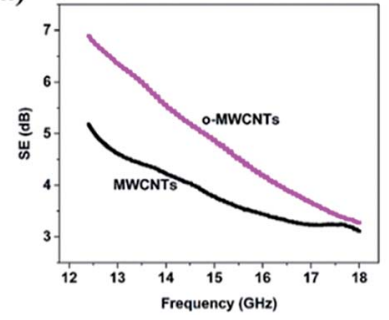

(b)

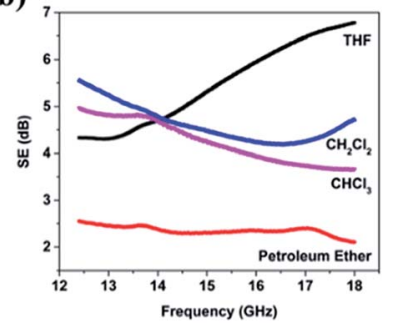

Fig. 1 EMI SE of: (a) the pristine MWCNT/silicone foam and oMWCNT/silicone foam composites using THF as dispersed solvent. (b) o-MWCNT/silicone foam composites with various dispersed solvent. The filler content of the composites is $5 \mathrm{wt} \%$. best EMI shielding performance. It is speculated that THF is an ideal solvent for homogeneous dispersion of o-MWCNTs in the silicone foam. Hence, o-MWCNTs were chosen as the fillers and THF was used as the dispersed solvent to prepare o-MWCNT/ silicone foam composites in the subsequent experiments.

The o-MWCNT/silicone foam mixture was stirred vigorously and poured into designed mould followed by foaming process to get uniformly dispersed composites with various shapes. The optical images of composites with various o-MWCNT content are shown in Fig. 2a-c. The composites exhibited porous architectures with excellent flexibility. The dispersion of $\mathrm{o}^{-}$ MWCNTs in the silicone foam matrix was confirmed by SEM images. Fig. $2 \mathrm{~d}$ shows a cellular structure with interconnected micro-open pores of pure silicone foam, whose surface is quite flat seen in the magnified SEM image. With the increasing oMWCNT content from 1 to $30 \mathrm{wt} \%$, the amount of o-MWCNTs in the silicone foam increased, as shown in Fig. 2e-i. OMWCNTs dispersed uniformly in the silicone foam and no agglomeration of o-MWCNTs was observed even at the high oMWCNT content because of the interfacial interactions between the o-MWCNTs and silicone foam. The interfacial interactions may primarily derive from two aspects: (1) the oxygen functional groups presented on the MWCNT walls could form hydrogen bonding interactions with silicone foam; (2) the $\pi$-system in the o-MWCNTs could form $\pi-\mathrm{CH}$ interactions with side chains of silicone foam. ${ }^{19}$ These interactions not only lead to the homogeneous dispersion of o-MWCNTs in the silicone foam, but also prevent the aggregation of o-MWCNTs which is beneficial to the formation of o-MWCNT conductive network.

According to the transmission line theory, the attenuation of electromagnetic waves occurs by three mechanisms: reflection, absorption and multiple reflections, so the $\mathrm{SE}_{\mathrm{T}}$ is the sum of all the three terms. If the distance between the reflecting surfaces or interfaces is considerably larger than the skin depth, the contribution from multiple reflections is merged in the absorption. ${ }^{20}$ Therefore, the $\mathrm{SE}_{\mathrm{T}}$ has the following expression:

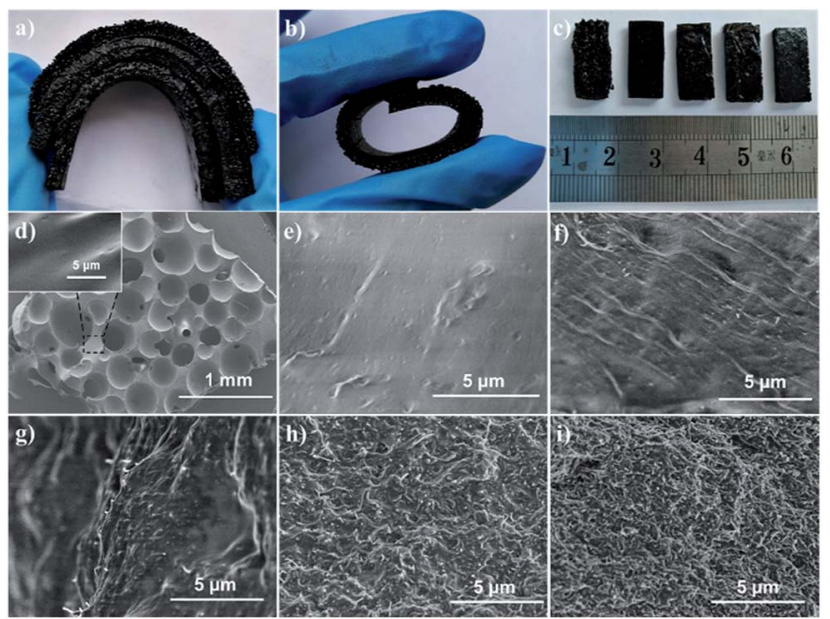

Fig. 2 Optical images of o-MWCNT/silicone foam composites with various o-MWCNT content: (a) (up to down) 1, 5 and $10 \mathrm{wt} \%$; (b) $1 \mathrm{wt} \%$; (c) (left to right) 1, 5, 10, 20 and $30 \mathrm{wt} \%$. SEM images: (d) silicone foam without o-MWCNTs; (e-i): o-MWCNT/silicone foam composites with various o-MWCNT content: 1, 5, 10, 20, 30 wt\%. 
(a)

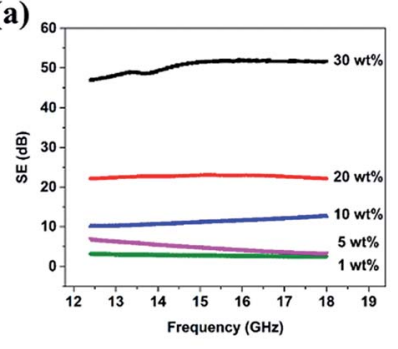

(c)

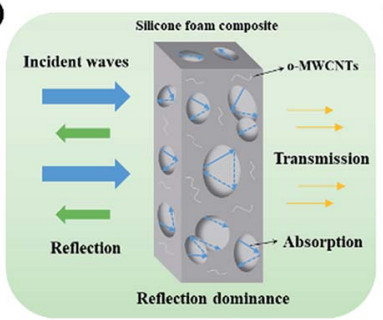

(b)

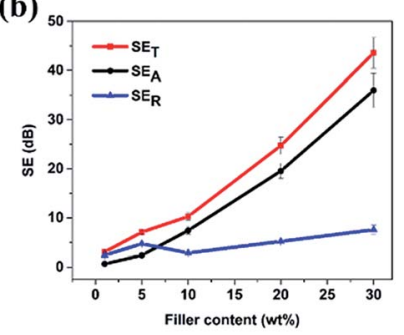

(d)

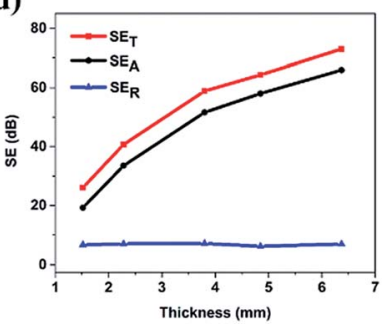

Fig. 3 (a) SE of O-MWCNT/silicone foam composites with various oMWCNT content. (b) $\mathrm{SE}_{\mathrm{A}}, \mathrm{SE}_{\mathrm{R}}$ and $\mathrm{SE}_{\mathrm{T}}$ at $12.4 \mathrm{GHz}$ of o-MWCNT/silicone foam composites as a function of o-MWCNT content. (c) Schematic representation of EMI shielding mechanism for O-MWCNT/ silicone foam composite. (d) $\mathrm{SE}_{\mathrm{A}}, \mathrm{SE}_{\mathrm{R}}$ and $\mathrm{SE}_{\mathrm{T}}$ at $12.4 \mathrm{GHz}$ of oMWCNT/silicone foam composites as a function of thickness. The thickness of the samples in (a) and (b) is around $2.5 \mathrm{~mm}$; error bars represent the standard deviation.

$$
\mathrm{SE}_{\mathrm{T}}(\mathrm{dB})=\mathrm{SE}_{\mathrm{R}}+\mathrm{SE}_{\mathrm{A}}
$$

Fig. 3a shows the EMI SE of o-MWCNT/silicone foam composites with various o-MWCNT content as a function of frequency. At the same content of o-MWCNT, the $\mathrm{SE}_{\mathrm{T}}$ of the composites is almost independent of frequency in the measured bands, which is consistent with other types of polymer composites such as MWNTs/PS/PMMA, ${ }^{21}$ MWCNT/PU ${ }^{22}$ and PS/MWCNT/Graphite Nanoplate Nanocomposites. ${ }^{23}$ As shown in Fig. $3 \mathrm{~b}$, the effect of o-MWCNT content on $\mathrm{SE}_{\mathrm{A}}, \mathrm{SE}_{\mathrm{R}}$ and $\mathrm{SE}_{\mathrm{T}}$ was studied at the frequency of $12.4 \mathrm{GHz}$. With the increasing o-MWCNT content from 1 to $30 \mathrm{wt} \%$, both $\mathrm{SE}_{\mathrm{T}}$ and $\mathrm{SE}_{\mathrm{A}}$ increased while $\mathrm{SE}_{\mathrm{R}}$ remained unchanged. For example, the average values of $\mathrm{SE}_{\mathrm{T}}, \mathrm{SE}_{\mathrm{A}}$ and $\mathrm{SE}_{\mathrm{R}}$ of o-MWCNT/silicone foam composites with $30 \mathrm{wt} \%$ o-MWCNTs were $40.2,33.3$ and $6.9 \mathrm{~dB}$, respectively, indicating the contribution of absorption (82.8\%) was much larger than that of reflection $(17.2 \%)$ at high oMWCNT content as shown in Fig. 3c. It is noteworthy that the maximum $\mathrm{SE}_{\mathrm{T}}$ can reach $47 \mathrm{~dB}$ with $30 \mathrm{wt} \%$ of o-MWCNTs, which is comparable or even superior to the reported polymers with the similar content of fillers. For instance, the $\mathrm{SE}_{\mathrm{T}}$ of $\mathrm{rGO} / \mathrm{PS},{ }^{24} \mathrm{rGO} / \mathrm{Fe}_{3} \mathrm{O}_{4} / \mathrm{PVA}^{25}$ and MWCNTs/PMMA ${ }^{26}$ is 29,15 and $27 \mathrm{~dB}$, respectively, as listed in the Table 1 that compares the EMI SE of various polymer composites reported in the literature.

It is well known that the EMI SE is not only dependent on the dispersion and content of the fillers, but also dependent on the thickness of the polymer composites. Fig. $3 \mathrm{~d}$ reveals the influence of sample thickness on the EMI SE at $30 \mathrm{wt} \%$ o-MWCNT loading. By increasing the sample thickness from 0.5 to 6.4 $\mathrm{mm}$, the $\mathrm{SE}_{\mathrm{T}}$ of o-MWCNT/silicone foam composites increased

from 26 to $73 \mathrm{~dB}$, which is high enough to meet the requirements for commercial applications and even the military applications. ${ }^{38}$ We can also see that $\mathrm{SE}_{\mathrm{A}}$ increased with the increasing sample thickness, whereas $\mathrm{SE}_{\mathrm{R}}$ was almost unchanged. According to shielding theory, $\mathrm{SE}_{\mathrm{A}}$ and $\mathrm{SE}_{\mathrm{R}}$ could be expressed as:

$$
\begin{gathered}
\mathrm{SE}_{\mathrm{A}}=8.686 \frac{d}{\delta} \\
\mathrm{SE}_{\mathrm{R}}=20 \log \frac{Z_{0}}{4 Z_{1}}
\end{gathered}
$$

where $d, \delta$ and $Z_{n}$ represent the thickness, skin depth and impedance of materials, respectively. ${ }^{39}$ Although the equations are used for conductive monolithic materials, it is desirable to analyze the general effect of thickness on the SE of foam composites using the equations above. ${ }^{40}$ From the eqn (5) and (6), $\mathrm{SE}_{\mathrm{A}}$ is a function of thickness while $\mathrm{SE}_{\mathrm{R}}$ is independent of thickness. Therefore, the thickness of composites has an impact on $\mathrm{SE}_{\mathrm{A}}$. The results of experiment are generally consistent with the theoretic analysis. Similar results were reported in the previous literature. ${ }^{16,41}$

In order to determine the shielding mechanism of oMWCNT/silicone foam composites, the reflection $(R)$, transmission $(T)$ and absorption $(A)$ coefficients were calculated based on the $S$ parameters. According to Fig. S4a, $\uparrow R$ coefficients were increased with growing filler content, which is mainly attributed to the enhanced electrical conductivity. ${ }^{17}$ The $R$ coefficients are higher than $A$ coefficients with various filler content, suggesting a reflection-dominant shielding mechanism. Additionally, the $R, T$ and $A$ coefficients slightly changed with the thickness of different samples.

The dielectric characteristics of o-MWCNT/silicone foam composites are given in Fig. S5. $\uparrow$ There are increases of complex permittivity (Fig. S5a and b $\dagger$ ), dielectric tangent loss (Fig. S5c $\dagger$ ) and AC conductivity (Fig. S5d†) with increasing o-MWCNT content, suggesting that more o-MWCNT conductive networks were formed. The increase of conductive networks, which act as dissipating mobile charge carriers, results in higher dielectric tangent loss and consequently higher attenuation of electromagnetic waves.

\section{Compression performance}

As is well-known, silicone foam possesses excellent mechanical properties, which makes them promising polymer for various practical applications. The compressive stress-strain curves of silicone foam can be divided into the elastic region, yielding region and densification region, while there is no clear boundary between the elastic region and yielding region. As shown in Fig. 4a, there was no obvious breakage observed in the curves before the stress of $6 \mathrm{MPa}$, indicating the superior mechanical property of silicone foam composites. The corresponding stress at the same strain of silicone foam composites increased with the increasing o-MWCNT content while the range of yielding region decreased. It demonstrated that the silicone foam composites with higher o-MWCNT content exhibited higher strength and hardness, by contrast, the 
Table 1 EMI shielding performance of various shielding materials

\begin{tabular}{|c|c|c|c|c|c|}
\hline Filler $^{a}$ & Filler [wt\%] & Thickness [mm] & Polymer $^{b}$ & EMI SE [dB] & Ref. \\
\hline o-MWCNTs & 30 & 2.5 & Silicone foam & 40 & This work \\
\hline MWCNTs & 40 & 0.165 & PMMA & 27 & 26 \\
\hline MWCNTs & 15 & 2.0 & PVDF & 57 & 27 \\
\hline MWCNTs & 15 & 2.8 & PEDOT & 58 & 28 \\
\hline SWCNT & 15 & 2 & Epoxy & 25 & 29 \\
\hline $\mathrm{CNF}$ & 15 & - & PS foam & 19 & 32 \\
\hline rGO & 30 & 2.5 & PS foam & 29 & 24 \\
\hline rGO & 10 & 2.3 & PEI & 22 & 15 \\
\hline rGO & 20 & 2.0 & Wax & 29 & 33 \\
\hline $\mathrm{rGO} / \gamma-\mathrm{Fe}_{2} \mathrm{O}_{3}$ & 75 & 2.5 & PANI & 51 & 34 \\
\hline $\mathrm{rGO} / \mathrm{Fe}_{3} \mathrm{O}_{4}$ & 35 & 0.3 & PVA & 15 & 25 \\
\hline
\end{tabular}

${ }^{a}$ SWCNT, single wall carbon nanotube; CNF, carbon nanofiber; rGO, reduced graphene oxide. ${ }^{b}$ PMMA, poly(methylmethacrylate); WPU, waterborne polyurethane; PVDF, poly(vinylidene fluoride); PEDOT, poly(3,4-ethylenedioxythiophene); PU, polyurethane; PS, polystyrene; PEI, polyetherimide; PANI, polyaniline; PVA, polyvinyl alcohol; PVC, polyvinyl chloride; SA, sodium alginate.

(a)

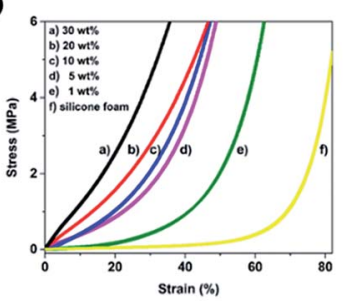

(c)

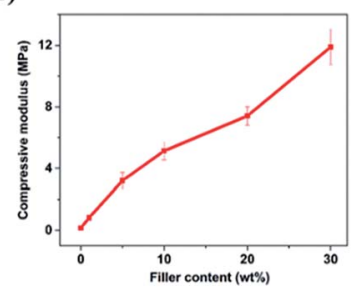

(b)

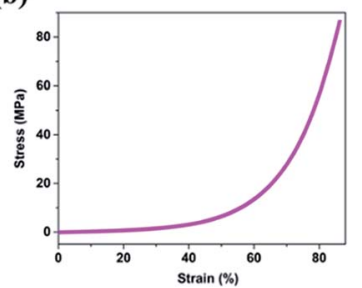

(d)

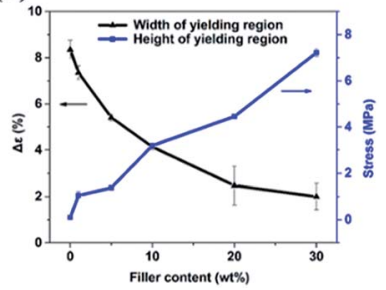

Fig. 4 (a) Compressive stress-strain curves of silicone foam. (b) Compressive stress-strain curve of $5 \mathrm{wt} \%$ o-MWCNT/silicone foam composite. (c) Compressive modulus and (d) the width $(\Delta \varepsilon)$ and the height $\left(\sigma_{\varepsilon=0.40}\right)$ of yielding region of o-MWCNT/silicone foam composites with various o-MWCNT content.

silicone foam composites with lower o-MWCNT content behaved more flexible. From Fig. 4b, the $5 \mathrm{wt} \%$ o-MWCNT/ silicone foam showed a compressive stress of 86.4 MPa at the strain of $86 \%$ without being broken. The o-MWCNT/silicone foam composites showed higher compressive strengths (several tens of MPa) than the porous MWCNT/WPU composites (several tens to hundreds of $\mathrm{kPa}$ ), which demonstrated that $\mathrm{o}^{-}$ MWCNT/silicone foam composites were strong and robust. ${ }^{5}$ When the o-MWCNT content increased from 1 to $30 \mathrm{wt} \%$, the compressive modulus of o-MWCNT/silicone foam increased by nearly 15 times from 0.8 to $11.9 \mathrm{MPa}$ (Fig. 4c).

The energy is absorbed through the deformation of silicone foam in the yielding region. The width and the height of yielding region are employed to quantitatively evaluate the compression performance of the silicone foam. The width of yielding region is the difference of strain in the stress of 400 and $200 \mathrm{kPa}$, representing the damping effect of materials. The height of yielding region is defined as the stress at the strain of $40 \%$, relating to the hardness and pressure resistance of materials.

The increasing content of o-MWCNTs led to a decrease in the width of yielding region (shown in Fig. 4d), which signified the reduction of the damping effect of o-MWCNT/silicone foam composites. It is mainly because the o-MWCNTs contained in the silicone foam may affect the foaming process and decrease the porosity of silicone foam. By contrast, the higher content of o-MWCNTs raised the height of yielding region (shown in Fig. 4d). Thus, the hardness and pressure resistance of silicone foam can be further enhanced by introducing $\mathrm{o}^{-}$ MWCNTs, which attributed to the hydrogen bonding interactions between the o-MWCNTs and siloxane chains.

\section{Gamma radiation resistance}

O-MWCNT/silicone foam composites were irradiated by $\gamma$-rays from a ${ }^{60} \mathrm{Co}$ source with various absorbed doses in order to investigate their gamma radiation stability. As shown in Fig. 5a, the EMI SE of composites was almost unchanged at low loading of o-MWCNTs while decreased slightly at the content of 20 and $30 \mathrm{wt} \%$ with the increasing absorbed doses from 100 to $500 \mathrm{kGy}$. The SE of $30 \mathrm{wt} \% \mathrm{o}-\mathrm{MWCNT} /$ silicone foam composites irradiated at $500 \mathrm{kGy}$ can reach $32 \mathrm{~dB}$, which still meets the requirements for applications. According to the literature, the gamma radiation induces the structural transformation of o-MWCNTs from the graphite structure to 
(a)

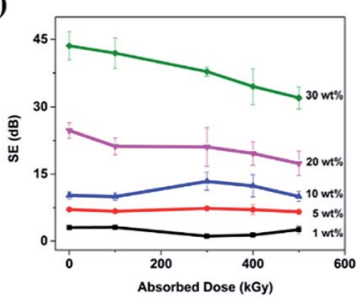

(b)

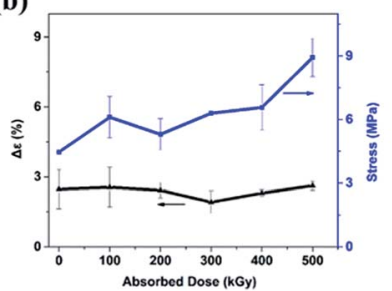

(c)

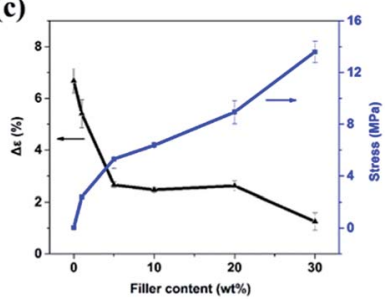

Fig. 5 (a) $\mathrm{SE}_{\mathrm{T}}$ of o-MWCNT/silicone foam composites as a function of absorbed doses with various o-MWCNT content. (b) The width and the height of yielding region of 20 wt\% o-MWCNT/silicone foam composites as a function of absorbed doses. (c) The width and the height of yielding region of o-MWCNT/silicone foam composites irradiated at $500 \mathrm{kGy}$ with various o-MWCNT content.

amorphous structure at high absorbed doses due to the increase of $\mathrm{sp}^{3}$ bonds and oxygen compositions. ${ }^{42}$ Thus, it is speculated that the destruction of o-MWCNT conductive network led to the reduction of SE. Nevertheless, the decline of SE was not remarkable, suggesting a stable EMI shielding property of o-MWCNT/silicone foam composites when exposed to gamma radiation.

The influence of gamma radiation with different absorbed doses on the mechanical properties is shown in Fig. 5b. The width of yielding region of $20 \mathrm{wt} \% \mathrm{o}-\mathrm{MWCNT} /$ silicone foam composite was nearly unchanged at the absorbed doses from 100 to $500 \mathrm{kGy}$. The absorbed doses had little influence on the damping effect of o-MWCNT/silicone foam composites, suggesting that the foam structure was not damaged by gamma radiation. In addition, the heights of yielding region increased with the increasing absorbed doses. The free radicals formed by gamma radiation could induce and improve the crosslinking of polymers, thus improving the hardness and pressure resistance of silicone foam composites. ${ }^{43,44}$ The silicone foam composites with various o-MWCNT content were irradiated at $500 \mathrm{kGy}$ and the mechanical behaviors are shown in Fig. $5 \mathrm{c}$. The width and the height of $30 \mathrm{wt} \% \mathrm{o}-\mathrm{MWCNT} / \mathrm{silicone}$ foam composite were $1.25 \%$ and $13.6 \mathrm{MPa}$ after irradiated at $500 \mathrm{kGy}$, by comparison, $1.99 \%$ and $7.2 \mathrm{MPa}$ were obtained without gamma radiation. The irradiated silicone foam composites exhibited a good mechanical property and a stable EMI shielding property, illustrating a high gamma radiation stability.

\section{Conclusions}

O-MWCNT/silicone foam composites with various o-MWCNT content were manufactured by solvent casting followed by foaming and cross-linking reactions. The as-prepared

composites exhibited superior EMI shielding performance and excellent mechanical properties due to the uniform dispersion of o-MWCNTs in silicone foam. After irradiated by gamma rays, o-MWCNT/silicone foam composites showed a relatively stable EMI shielding property and an improvement of the hardness and pressure resistance. The o-MWCNT/silicone foam composites with high resistance to gamma radiation are promising candidates for EMI shielding in space and nuclear radiation environment.

\section{Conflicts of interest}

There are no conflicts to declare.

\section{Acknowledgements}

This work was supported by the Science Challenge Project (No. TZ2018004) and National Natural Science Foundation of China (Project No. 11575009, 11505011, 11375019).

\section{Notes and references}

1 S. Biswas, S. S. Panja and S. Bose, J. Mater. Chem. C, 2018, 6, 3120-3142.

2 F. Shahzad, M. Alhabeb, C. B. Hatter, B. Anasori, S. M. Hong, C. M. Koo and Y. Gogotsi, Science, 2016, 353, 1137-1140.

3 Y. Wang, L.-j. Ni, F. Yang, F.-q. Gu, K. Liang, K. Marcus, Y.-d. Wan, J.-j. Chen and Z.-s. Feng, J. Mater. Chem. C, 2017, 5, 12769-12776.

4 R. Na, J. Liu, G. Wang and S. Zhang, RSC Adv., 2018, 8, 32963303.

5 Z. Zeng, H. Jin, M. Chen, W. Li, L. Zhou and Z. Zhang, Adv. Funct. Mater., 2016, 26, 303-310.

6 L. Xu, L.-C. Jia, D.-X. Yan, P.-G. Ren, J.-Z. Xu and Z.-M. Li, RSC Adv., 2018, 8, 8849-8855.

7 T. K. Gupta, B. P. Singh, S. R. Dhakate, V. N. Singh and R. B. Mathur, J. Mater. Chem. A, 2013, 1, 9138-9149.

8 M. F. L. D. Volder, S. H. Tawfick, R. H. Baughman and A. J. Hart, Science, 2013, 339, 535-539.

9 M. H. Al-Saleh, W. H. Saadeh and U. Sundararaj, Carbon, 2013, 60, 146-156.

10 V. Datsyuk, M. Kalyva, K. Papagelis, J. Parthenios, D. Tasis, A. Siokou, I. Kallitsis and C. Galiotis, Carbon, 2008, 46, 833-840.

11 T. A. Saleh, Appl. Surf. Sci., 2011, 257, 7746-7751.

12 H.-B. Chen, B. Liu, W. Huang and W.-H. Wu, Polym. Degrad. Stab., 2015, 114, 89-93.

13 K. Cao, Y. Ao, J. Chen, J. Peng, W. Huang, J. Li and M. Zhai, J. Appl. Polym. Sci., 2017, 134, 45404.

14 Z. Chen, C. Xu, C. Ma, W. Ren and H.-M. Cheng, Adv. Mater., 2013, 25, 1296-1300.

15 J. Ling, W. Zhai, W. Feng, B. Shen, J. Zhang and W. Zheng, ACS Appl. Mater. Interfaces, 2013, 5, 2677-2684.

16 B. Shen, Y. Li, W. Zhai and W. Zheng, ACS Appl. Mater. Interfaces, 2016, 8, 8050-8057.

17 W.-L. Song, M.-S. Cao, M.-M. Lu, S. Bi, C.-Y. Wang, J. Liu, J. Yuan and L.-Z. Fan, Carbon, 2014, 66, 67-76. 
18 S. P. Pawar, D. A. Marathe, K. Pattabhi and S. Bose, J. Mater. Chem. A, 2015, 3, 656-669.

19 R. Verdejo, F. Barroso-Bujans, M. A. Rodriguez-Perez, J. A. d. Saja, M. Arroyo and M. A. Lopez-Manchado, J. Mater. Chem., 2008, 18, 3933-3939.

20 A. Chaudhary, R. Kumar, S. Teotia, S. K. Dhawan, S. R. Dhakate and S. Kumari, J. Mater. Chem. C, 2017, 5, 322-332.

21 R. Rohini and S. Bose, ACS Appl. Mater. Interfaces, 2014, 6, 11302-11310.

22 Z. Zeng, M. Chen, H. Jin, W. Li, X. Xue, L. Zhou, Y. Pei, H. Zhang and Z. Zhang, Carbon, 2016, 96, 768-777.

23 S. Maiti, N. K. Shrivastava, S. Suin and B. B. Khatua, ACS Appl. Mater. Interfaces, 2013, 5, 4712-4724.

24 D.-X. Yan, P.-G. Ren, H. Pang, Q. Fu, M.-B. Yang and Z.-M. Li, J. Mater. Chem., 2012, 22, 18772-18774.

25 B. V. Rao, P. Yadav, R. Aepuru, H. S. Panda, S. Ogale and S. N. Kale, Phys. Chem. Chem. Phys., 2015, 17, 18353-18363.

26 H. M. Kim, K. Kim, C. Y. Lee and J. Joo, Appl. Phys. Lett., 2004, 84, 589-591.

27 H. Wang, K. Zheng, X. Zhang, X. Ding, Z. Zhang, C. Bao, L. Guo, L. Chen and X. Tian, Compos. Sci. Technol., 2016, 125, 22-29.

28 M. Farukh, A. P. Singh and S. K. Dhawan, Compos. Sci. Technol., 2015, 114, 94-102.

29 Y. Huang, N. Li, Y. Ma, F. Du, F. Li, X. He, X. Lin, H. Gao and Y. Chen, Carbon, 2007, 45, 1614-1621.

30 Z. Liu, G. Bai, Y. Huang, Y. Ma, F. Du, F. Li, T. Guo and Y. Chen, Carbon, 2007, 45, 821-827.

31 Y. Yang, M. C. Gupta, K. L. Dudley and R. W. Lawrence, Nano Lett., 2005, 5, 2131-2134.
32 Y. Yang, M. C. Gupta, K. L. Dudley and R. W. Lawrence, Adv. Mater., 2005, 17, 1999-2003.

33 B. Wen, X. X. Wang, W. Q. Cao, H. L. Shi, M. M. Lu, G. Wang, H. B. Jin, W. Z. Wang, J. Yuan and M. S. Cao, Nanoscale, 2014, 6, 5754-5761.

34 A. P. Singh, M. Mishra, P. Sambyal, B. K. Gupta, B. P. Singh, A. Chandra and S. K. Dhawan, J. Mater. Chem. A, 2014, 2, 3581-3593.

35 K. Yao, J. Gong, N. Tian, Y. Lin, X. Wen, Z. Jiang, H. Na and T. Tang, RSC Adv., 2015, 5, 31910-31919.

36 B. Shen, W. Zhai, M. Tao, J. Ling and W. Zheng, ACS Appl. Mater. Interfaces, 2013, 5, 11383-11391.

37 F. Fang, Y.-Q. Li, H.-M. Xiao, N. Hu and S.-Y. Fu, J. Mater. Chem. C, 2016, 4, 4193-4203.

38 N. F. Colaneri and L. W. Shacklette, IEEE Trans. Instrum. Meas., 1992, 41, 291-297.

39 M. H. Al-Saleh and U. Sundararaj, Carbon, 2009, 47, 17381746.

40 J. Ma, M. Zhan and K. Wang, ACS Appl. Mater. Interfaces, 2015, 7, 563-576.

41 T. K. Gupta, B. P. Singh, V. N. Singh, S. Teotia, A. P. Singh, I. Elizabeth, S. R. Dhakate, S. K. Dhawan and R. B. Mathur, J. Mater. Chem. A, 2014, 2, 4256-4263.

42 B. Safibonab, A. Reyhani, A. N. Golikand, S. Z. Mortazavi, S. Mirershadi and M. Ghoranneviss, Appl. Surf. Sci., 2011, 258, 766-773.

43 M. Saiyad, N. M. Devashrayee and R. K. Mewada, Composites, Part B, 2014, 57, 71-79.

44 Y. Wang, J. Qiu, J. Peng, J. Li and M. Zhai, J. Mater. Chem. A, 2017, 5, 12393-12399. 